\title{
Levinas y las Ciencias Sociales: fundamentos epistémicos desde la alteridad ${ }^{1}$
}

\author{
Levinas and Social Sciences: \\ epistemic foundations from alterity
}

\author{
Luis Guillermo Jaramillo Echeverri² \\ Juan Carlos Aguirre García ${ }^{3}$
}

\section{Resumen:}

El artículo expone algunas de las tesis fundamentales del filósofo lituano-francés Emmanuel Levinas, especialmente, las que sustentan su filosofía de la alteridad, con el fin de poner en discusión la posibilidad de asumirlas como fundamentos epistemológicos de las Ciencias Sociales. Consta de cinco partes: en la primera, se inscribe a Levinas en el marco de la reflexión sobre las Ciencias sociales. La segunda, tercera y cuarta abordan la propuesta levinasiana bajo las categorías de Totalidad, Rostro y Lenguaje, respectivamente. El artículo culmina con unas aproximaciones epistemológicas que, más que formular puntos de llegada, sugieren rutas para posteriores desarrollos.

\section{Palabras Clave:}

Ciencias Sociales, totalidad, rostro, lenguaje, epistemología.

\section{Abstract:}

In order to consider the possibility of assuming them as the epistemic foundations of Social Sciences, this paper presents some of the essential theses of the French-Lithuanian philosopher, Emmanuel Levinas. In particular, the theses that support his philosophy of alterity are discussed. The paper is organized in five sections: First, Levinas is brought into the reflection framework about Social Sciences. Second, third and fourth sections go into the "Levinasian" proposal, under the categories of Totality, Face and Language, respectively. Finally, some epistemic views are presented to suggest further developments rather than final explanations.

Keywords:

Social Sciences, totality, face, language, epistemology.

Artículo recibido el 19 de julio de 2009 y aprobado el 30 de abril de 2010

1 El presente artículo hace parte de las discusiones del grupo de investigación: Fenomenología y Ciencias; reflexiones que se vienen desarrollando desde el año 2004 y que se consolidan en líneas teóricas que involucran tanto cuestiones epistemológicas, como rutas de acción en Investigación para las Ciencias Sociales y las Didácticas de las Ciencias.

2 Doctor en Ciencias Humanas y Sociales - Educación. Universidad Tras-os-Montes (Portugal). Profesor Universidad del Cauca, ljaramillo@unicauca.edu.co

3 Magíster en Filosofía, Universidad de Caldas. Profesor Universidad del Cauca. jcaguirre@unicauca. edu.co 


\section{Introducción}

En sus indagaciones sobre lo humano, las llamadas Ciencias Sociales necesariamente asumen una postura sobre el hombre. Pareciera que la cuestión de la pregunta por lo humano, la esencia de lo humano, ya hubiera sido superada por los humanismos posbélicos, con las confrontaciones intensas que suscitaron; sin embargo, toda "ciencia" del hombre, por no decir toda ciencia, está llamada a no perder de vista su objeto, es decir, hacia donde se dirige el “del”. Escudriñar en las obras de Levinas, dirigiendo la mirada hacia las Ciencias Sociales, será la oportunidad de repensar una pregunta inactual aunque, siguiendo la enmarañada red de pensamientos del filósofo lituano-francés, actual es todo lo que está encerrado en la patencia del ser-en-acto, representación en la conciencia intencional. In-actual será lo otro que lo actual, pues en el pensamiento occidental "la inteligibilidad última es la actualidad del ser en acto, la coexistencia de términos en un tema, la relación, la coherencia de lo uno y lo otro, a pesar de su diferencia, el acuerdo de lo diferente en el presente. El sistema. Lo uno significa lo otro y es significado por él, cada uno es signo del otro" (Levinas, 1998a, p. 14). Evidencia clara de total sujeción del otro por parte del mismo.

En el dominio de lo actual, toda significación está englobada en la verdad del sistema, quedando por fuera, como ajeno, el resto de lo humano. La propuesta in-actual de Levinas, además de poner en cuestión la inteligibilidad que se esconde tras la ciencia -por más humana que pretenda ser-es un intento por situar las Ciencias Sociales en un terreno donde lo teórico aún no ha encontrado sus certezas, de ahí la pregunta que lanza: “'no remonta la inteligibilidad, más acá de la presencia, a la proximidad del otro?" (ibíd.) Esta pregunta exigirá recurrir a lo in-actual, entre lo que se puede destacar: a) la impugnación de la totalidad y del concepto de verdad que de ella brota; b) la alteridad, entendida como la diferencia del "mismo" y el "otro", diferencia que no se basta en el reconocimiento, sino que la categoría de "Rostro" exige la responsabilidad irreductible a cualquier sistema; c) la consideración del lenguaje como una dimensión que no se agota en lo dicho ni en el discurso que expone el resultado de la síntesis judicativa kantiana, sino que reclama la voz de sutil silencio que hace señas al Otro. Como fundamento de todo esto, la Ética, que no se plantea como simple discurso de buenas maneras, sino obsesión por el otro hombre; no encerrado en un género (humanidad), sino Otro (Autrui, próximo) que se impone y llega a mí de modo traumático, dejándome sin capacidad de opción.

Antes de desplegar cada uno de los puntos señalados es importante recalcar que la mayor preocupación de Levinas, tal y como lo muestra Critchley (2004), consiste en aclarar al pensamiento contemporáneo que "la ética es la primera filosofía, entendiendo por "ética" una relación de responsabilidad infinita hacia los demás" (p. 12). Esta reubicación de la ética por encima de la metafísica, tradicionalmente concebida como prima philosophia, y de la epistemología reinante durante la modernidad, hace que muchos especialistas en la obra de Levinas adopten posturas radicales respecto a la interpretación de sus textos, alejándolo de cualquier referencia a lo político o a lo epistemológico. En la filosofía política y del derecho, sin embargo, se han ido realizando esfuerzos por considerar las propuestas levinasianas; véase por ejemplo: Dussel (2004), Hendley (2004), Burggraeve (2005), Loumansky (2006). Similar esfuerzo se ha venido haciendo en la reflexión sobre lo humano, aunque tienen la característica de asumir algunas tesis fuertes de Levinas que se combinan con las necesidades típicas de la disciplina particular en un aspecto específico; casos como estos pueden ser: Todd (2003), Lippitz (2007) y Jaramillo y Aguirre (2008) en el contexto educativo; Aguirre (2007) y Guenther (2007) en el contexto medioambiental; van Hooft (2003) y Dueck \& Parsons (2007) en el contexto de la salud. No obstante, no ha habido una reconstrucción sistemática de las posibilidades que Levinas ofrece tanto a la filosofía como a las metodologías de las Ciencias Sociales 4 . Este escrito es una aproximación a tales posibilidades.

4 Una primera reconstrucción fue hecha en Aguirre y Jaramillo (2006), aunque en ella sólo se abordó la relación objeto-sujeto en la investigación en Ciencias Sociales y la superación de tal dicotomía a partir de la propuesta levinasiana. 
No quiere decirse con lo anterior que es forzosa la interpretación de Levinas a la luz de la epistemología de las Ciencias Sociales. En un breve apartado titulado, precisamente, Las ciencias humanas y también Levinas, de forma condensada, esbozan un programa susceptible de abordaje. En tal apartado subraya las siguientes ideas:

a. Se ha vuelto cotidiano decir que en las Ciencias Humanas se escuchan los ecos de los gritos que proclaman el "fin del humanismo" y la "muerte del hombre". Estos eslóganes dan cuenta de un estado de la investigación donde la preocupación por el rigor torna desconfiados a psicólogos, sociólogos, historiadores y lingüistas respecto al Yo. Por esto, "se impone un formalismo para domesticar la salvaje proliferación de hechos humanos que, abordados en su contenido, nublan la vista del teórico; formalismo que se impone para medir la propia certeza del saber, más seguro de los límites de sus presupuestos axiomáticos que de cualquier axioma" (Levinas, 1998b, p. 81). En este sentido, la propuesta levinasiana tiende hacia los hechos (manifestaciones) humanos con una actitud que supera la domesticación que pretende el formalismo para proclamar la gloria de lo Infinito.

b. Las Ciencias Humanas han caído en una especie de romanticismo que intenta, desde el discurso, hablar bien del hombre, contribuyendo esto a la proliferación de disciplinas "sin contacto con la realidad de la violencia y la explotación" (Levinas, 1998b, p. 82). La reflexión sobre lo humano está impregnada del llamado a la responsabilidad; por tanto, la investigación social aséptica, en la que se privilegia la neutralidad del observador y la contundencia de los hechos, es digna de sospecha pues no tiene en cuenta el "Rostro" y el "Sufrimiento" como aspectos de lo humano que sobrepasan todo intento de tematización.

c. Finalmente, como fruto de la aspiración por imitar las Ciencias Naturales y sus proyectos matematizadores, así como la distancia que se permite el investigador social de las realidades que confronta, se ha perdido el rol de las Ciencias
Humanas en la sociedad actual (basta ver la baja demanda de ingreso y las pobres partidas que se destinan a las Facultades de Ciencias Sociales en nuestro continente), haciéndose incapaz de afrontar la angustia que carcome nuestras sociedades. Levinas afirma: "[la angustia] Proviene de la experiencia de las revoluciones que se hunden en la burocracia y en la represión; de la experiencia de las violencias totalitarias que se hacen pasar por revoluciones. Porque, en ellas, se aliena la desalienación misma" (Levinas, 1998b, p. 84). Se hace urgente, por tanto, resituar la crítica a la totalidad e indagar por la utopía de lo "Infinito".

En la propuesta de Levinas veremos, entonces, una postura similar a lo que Giri (2006) denominó: «Investigación Social Creativa, donde no bastan las simples denuncias (esto, quizás se aleje un poco de lo que a primera vista pareciera una cercanía con la Escuela de Frankfurt, véase Alford, 2002), sino que se asuman "críticas relevantes, y teorías y métodos transformativos que facilitarían la investigación crítica y creativa” (Giri, 2006, p. 227). Obviamente, la primera fase será indagar en sus textos y, en un trabajo posterior, habría que abrir discusiones y articulaciones entre Levinas y otras propuestas de la epistemología de las Ciencias Sociales.

\section{La separación de las Ciencias Sociales del discurso de la Modernidad: infinitud y verdad}

El sello de la Modernidad lo marca, sin lugar a dudas, el surgimiento de una ciencia profundamente diferente a la antigua o medieval; en el siglo pasado varios pensadores narraron de modo magistral lo característico de esta naciente adquisición humana (véase, por ejemplo, Husserl (1991), Heidegger (1998), Foucault (2001), Gadamer (1993)). Como una breve radiografía de esa época podemos citar:

La ciencia se convierte en la gran empresa de penetración en ámbitos desconocidos, para la que no urge un apoyo ni humano ni divino. Su camino de la investigación metódica significa 
autoaseguramiento de la razón. Pues sólo un Dios malintencionado podría llevar "la ciencia" a su perdición (caso que se le antojase confundir nuestra razón matemática). Ahora ya no se trata de la contemplación especulativa de la creación divina en su aparente plenitud de la forma, en la que la sabiduría divina puede venerarse: en la abstracción matemática se descubren regularidades que están ocultas a los sentidos. Sólo en el camino de la matematización del conocimiento de la experiencia se aproxima el investigador a la meta nunca definitivamente alcanzable: entender el libro de la naturaleza que Dios ha escrito con sus manos (Gadamer, 1993, pp. 30-31).

Gadamer condensa varias características de la ciencia moderna: a) la ciencia irrumpe en los más recónditos confines; incluso, los tradicionalmente vedados por las creencias religiosas o las potencias cognoscitivas; b) en la ciencia moderna se entroniza el método que ya no requiere la luz divina, ni siquiera la intervención creativa del hombre pues el método asegura el conocimiento, sólo basta su aplicación; c) la razón se torna cálculo y la matemática es su instrumento más excelso; d) lo patente se vuelve digno de desconfianza, lo que aparece oculta un trasfondo al que es preciso acceder; e) con el método y la matemática todo cae bajo el dominio de la experiencia, todo es susceptible de comprensión, si bien no agotable, sí cierta y acumulable.

Esta imagen de ciencia se instaura no sólo entre quienes indagan en el ámbito natural, sino también entre los estudiosos de lo social. Aunque varias voces se han levantado para reivindicar un carácter diverso de los estudios sociales frente a la univocidad pretendida por la ciencia moderna, aún es difícil establecer la identidad de las Ciencias Sociales; más aún, todavía se conservan muchas tesis de filósofos de la ciencia pertenecientes a la hoy llamada Concepción Heredada5, tesis que se creían superadas y

5 La 'concepción heredada' (received view) es el nombre con el que se agrupa a los filósofos de la ciencia que surgieron en el período entre guerras (siglo XX) y que tuvieron enorme vigencia hasta el advenimiento de la Revuelta Historicista (Kuhn, Lakatos, Feyerabend, Toulmin y otros). Entre los filósofos de la ciencia de ese período se encuentran los filósofos del Círculo de Viena, los del Círculo de Berlín y Popper. que hablaban de monismo metodológico, de una ciencia dependiente de lo empírico y de hechos que se traducen en enunciados con sentido. Como ejemplo de ello leamos a Haack (2002):

Los monistas metodológicos insisten en que las ciencias sociales usan "el método científico" tal y como lo hacen los físicos o los químicos. Los dualistas metodológicos sostienen que el método de la Ciencia Social es sui generis, una cuestión no de explicación causal, sino de "comprensión" ("una estrategia de profundo aliento seguida de asociación libre", según el maravilloso sarcasmo de Braithwaite) Pero esta es una falsa dicotomía: como toda investigación empírica, la ciencia social intencional descansa en la experiencia y los razonamientos; sólo requiere, en vez de microscopios o telescopios, cuestionarios bien diseñados, experimentos doble-ciego, test de significado estadístico, y cosas por el estilo (Ibíd. p. 36).

El planteamiento de Levinas con respecto a las Ciencias Sociales no puede alejarse de este campo de debate (¿o de batalla?6); no obstante, no se restringe a la defensa de un pluralismo metodológico, ni se ocupa de renovar las técnicas o instrumentos de investigación; su preocupación no se circunscribe a la clásica distinción entre explicación y comprensión. No significa esto entonces que su propuesta no pueda ser leída desde la óptica de las Ciencias Sociales; al contrario, las tesis que plantea se remontan a cuestiones originarias, cuestiones que exigen salirse del escenario tradicionalmente levantado para considerarlas y, en consecuencia, permitirán refrescar los discursos que, o bien se limitan a defender la similitud de las Ciencias Sociales con el operar de las Ciencias Naturales, o bien sucumben ante la posibilidad de encontrar verdades en los estudios sociales. Este apartado señalará, aunque brevemente, la exigencia de considerar los debates sobre las Ciencias Sociales fuera de lo denominado por Levinas Totalidad; además,

6 Muchas discusiones sobre estos temas se han agrupado bajo la denominación Science Wars (para una protohistoria de las Guerras de la ciencia, ver Theocharis, 1997). 
se intentará mostrar cómo sólo con la superación de la Totalidad podremos comprender radicalmente el significado de verdad.

Tal y como lo sugerimos con Gadamer, a partir de la Revolución Copernicana7 se confió a la razón científica la tarea de explicar el libro de la naturaleza; sus éxitos en los descubrimientos teóricos y prácticos fueron invadiendo todos los dominios de la realidad, incluso de lo humano. El giro consistió en invertir los términos de la relación: anteriormente, la naturaleza y el hombre eran considerados criaturas, objetos dignos de admiración y contemplación; después, naturaleza y hombre quedaron circunscritos al pensamiento que los piensa y hace que ellos digan lo que el pensador quiere escuchar. En el giro tanto naturaleza como hombre pierden su carácter de exterioridad, de estar fuera de mi conciencia, y empiezan a hacer parte de la "Mismidad". Si bien este proceso lo percibe Levinas no sólo en relación con lo humano (la alteridad la sitúa primordialmente en la relación cara-a-cara), también podrían hacerse análisis valiosos respecto a las Ciencias Naturales donde el objeto no es tomado como tal, sino que integra un sistema teórico que lo aborda desde una perspectiva prefijada, escindiendo de él aquello que no encuadre con las pretensiones heurísticas8. Sin embargo, como nuestra reflexión se dirige a las Ciencias Sociales, nos limitaremos a ello.

Según Levinas, el sello del pensamiento occidental lo constituye la Totalidad. Es importante notar cómo desde Bacon se accedía a la naturaleza, lo otro que yo, con el deseo de saber de ella, conocerla; los deseos de saber se fueron satisfaciendo en la medida en que los resultados obtenidos concordaban

7 Asumimos como Revolución Copernic ana, no sólo el dato histórico de la intuición heliocéntrica, sino el profundo impacto que esto tuvo en el pensamiento moderno; en este sentido, por Revolución Copernicana retomamos el optimismo kantiano para quien "la razón sólo reconoce lo que ella misma produce según su bosquejo [...] La razón tiene que anticiparse con los principios de sus juicios de acuerdo con leyes constantes y [...] tiene que obligar a la naturaleza a responder sus preguntas, pero sin dejarse conducir con andaderas [...] La razón debe abordar la naturaleza [pero] no lo hará en calidad de discípulo que escucha todo lo que el maestro quiere, sino como juez designado que obliga a los testigos a responder a las preguntas que él les formula" (Kant, 2000, p. 18).

8 Por heurística se entiende aquí el conjunto de técnicas usadas para indagar y descubrir. fielmente con lo que se esperaba. Pero Levinas se dirige hacia ese deseo, contraponiéndolo a un deseo del "otro" que denomina metafísico:

Lo Otro metafísicamente deseado no es "otro" como el pan que como, o como el país en que habito, como el paisaje que contemplo, como a veces, yo mismo a mí mismo, este "yo", este "otro". De estas realidades, puedo "nutrirme" $y$, en gran medida, satisfacerme, como si me hubiesen simplemente faltado. Por ello mismo, su alteridad se reabsorbe en mi identidad de pensante o de poseedor. El deseo metafísico tiende hacia lo totalmente otro, hacia lo absolutamente otro (Levinas, 1977, p. 57).

Se ha planteado una distinción radical: el deseo de un ser indigente que necesita de algo para satisfacerse y el deseo metafísico. En el primer sentido, se da una relación entre quien desea y lo deseado; relación reversible de polos que se acoplan en un sistema: "En este caso, el Mismo y lo Otro se encontrarían reunidos bajo una mirada común y la distancia absoluta que los separa sería suprimida" (Levinas, 1977, p. 60). La supresión se da en varias instancias: en primera instancia, al interior del Mismo: yo que se mira "como si" fuese otro en su interioridad, concluyendo que no hay tal distinción y confirmando su identidad $(\mathrm{A}=\mathrm{A})$; en segunda instancia, yo que se enfrenta al mundo como lo distinto de sí, pero yo que con el tiempo se habitúa, "encuentra en el mundo un lugar y una casa" (Levinas, 1977, p. 61) y el mundo se torna "a la mano", como posibilidad y espacio para ejercer mi libertad, siendo dueño y señor de todo lo extraño; incluso, de mis congéneres. En última instancia, yo que se encuentra ante el Otro y lo re-presenta de acuerdo con imágenes previas, lo comprende basado en situaciones anteriormente vividas, lo adecua a lo conocido y lo subsume en pensamiento cogitante. Estas tres instancias configuran las relaciones enmarcadas en la Totalidad, yo y otro encapsulados en un sistema cerrado, donde la alteridad se suprime y todo queda reducido a Mismo.

Es precisamente la ruptura de la alteridad lo que permite establecer relaciones de adecuación: donde hay elementos comparativos es posible enunciar uniformidades que podrían ir alcanzando paulati- 
namente mayores niveles de abstracción y universalidad. Si recurrimos a la clásica definición de verdad como: adequatio rei et intellectus, tendremos que la distancia absoluta entre la cosa (yo, mundo, otro) y la mente se torna relativa, como relativa queda su alteridad. En este sentido la ciencia, cualquier ciencia, incluyendo la social, que tiende al establecimiento de la verdad, está anclada en la Totalidad: "el ser sólo puede ser verdadero si es totalidad. La verdad debe comprender hasta aquellos errores que, excluidos, se llevarían a "otra parte" y reducirían la totalidad a una parte, es decir, a una abstracción. Contrario a la concepción criticista del saber, el pensamiento verdadero es ruptura con lo inmediatamente dado, con lo intuitivo. [Por consiguiente] la verdadera función del pensamiento totalizante no consiste en mirar el ser, sino en determinarlo en su organización" (Levinas, 2006, p. 64).

Por otra parte, las Ciencias Sociales también quedan inmersas en la Totalidad desde los cánones interpretativos. Levinas analiza el caso de la hermenéutica: la intelección de un texto o de una obra cultural -podríamos agregar: de una manifestación social-, se da por una vía diferente a la pretendida por Descartes; o sea, supera la intelección por las naturalezas simples en sí mismas; si bien también va de las partes al todo, las partes tienen su sentido en la totalidad: "había un círculo en el pensamiento totalizante y analizante al que podríamos llamar vicioso, de esta manera, el análisis y la síntesis se presuponen mutuamente" (Levinas, 2006, p. 66). Con Heidegger, la presuposición del análisis y de la síntesis puede llevar no ya a un círculo vicioso, donde el movimiento lineal sea la característica, sino a un círculo hermenéutico que opera de un modo más homogéneo; en este movimiento circular, el todo y las partes se determinan. Para comprender la totalidad habría necesidad de saltos progresivos: saber entrar en el círculo hermenéutico, sobrepasar la inmediatez en la que las partes son dadas, asumir los malentendidos como partes: "noción de totalidad y de intelecto que conducirá a comprender toda experiencia, y puede ser razonamiento total sobre las cosas, acorde con el modelo de interpretación de textos. ¡Noción de totalización siempre reco- menzando, noción de totalidad abierta!" (ibíd.), más no por abierta la totalidad heideggeriana, deja de ser totalidad.

Ahora bien, con el "Deseo" metafísico se asume un segundo sentido. Levinas aboga por la ruptura con la Totalidad, la cual desafía el concepto de verdad esgrimido hasta el momento, al demostrar su contradicción: el conocimiento de la verdad supone un movimiento en el cual lo "Otro" se reduce a la medida del pensamiento del investigador; en este sentido, la verdad hallada no es más que una verdad que está en el sujeto y que aspira a confrontar; el "Otro" se reduce a confirmar lo que ya estaba en el "Mismo", legitimándose así el ideal socrático de no recibir nada del otro pues basta conocerse a sí mismo. Polémicamente, Levinas plantea un sentido más radical de verdad, pero ello exige trascender la Totalidad e ir tras la búsqueda de lo Infinito; de tal manera que "Deseo" en este contexto será:

\section{Deseo de lo absolutamente Otro. Fuera del hambre que se satisface, de la sed que se calma y de los sentidos que se aplacan, la metafísica desea lo Otro más allá de las satisfacciones, sin que sea posible realizar con el cuerpo algún gesto para disminuir la aspiración, sin que sea posible esbozar alguna caricia conocida, ni inventar alguna nueva caricia. Deseo sin satisfacción que, precisamente, espera el alejamiento, la alteridad y la exterioridad del Otro (Levinas, 1977, p. 58).}

De acuerdo con esta caracterización de Deseo metafísico, la búsqueda de la verdad y su concretización en formas y abstracciones no será el objeto de la relación con el Otro; más aún, en los términos planteados por la Totalidad este conocimiento es reducido. La relación con el Otro tendrá que contemplar a éste como Infinito ${ }^{9}$, lo que equivale a decir que pensar al Otro no consiste en pensar un objeto.

9 Aunque generalmente este concepto ha sido ligado a la divinidad y el propio Levinas es un filósofo que no rehúsa su ser judío, Infinito es uno de los términos que más desarrollo filosófico ha tenido dentro de la obra del autor. Para las pretensiones del artículo, nos bastará consignar que Infinito en Levinas no tendrá ninguna referencia teológica ni abstracta; para él: “la experiencia, la idea de lo infinito, está en la relación con el Prójimo. La idea de lo infinito es la relación social" (Levinas, 2005a, p. 247). 
Obviamente, la concepción de verdad adquirirá otra connotación: a) el Otro es in-adecuado a las expectativas del pensador; el Otro se revela: "el movimiento parte de lo pensado y no del pensador" (Levinas, 1977; p. 85). b) en tanto relación con lo Infinito, la teoría, resultado al que tiende la investigación, cede su primado a la búsqueda de la verdad (en términos de Deseo); c) la relación con el Otro trasciende el afán cognoscitivo y exige respuesta: "la inmortalidad no es el objetivo del primer movimiento del Deseo, sino el Otro, el Extranjero. Es absolutamente no-egoísta, su nombre es justicia" (Levinas, 1977; p. 87). Los próximos apartados considerarán estos aspectos bajo las categorías de Rostro y Lenguaje, siempre teniendo la Ética como suelo privilegiado; todo esto a su vez nos permitirá esbozar, en la parte final, algunas aproximaciones epistemológicas para las Ciencias Sociales.

\section{Rostro y Ciencias Sociales: lo infinito de la separación}

En el apartado anterior veíamos cómo la correlación ser-saber se encuentra afincada a un pensamiento de lo igual (totalizante); "ser que es, en la verdad, abarcado" (Levinas, 1991, p. 85). Recordemos que para la filosofía primera o metafísica, existe un ser pensante que puede comprender lo real por la vía cognoscitiva; pensamiento finito que se sabe en la simetría Mismo-Otro, lo demás, es tan sólo ilusión. A esta finitud Levinas contrapone la idea de lo infinito como pensamiento de lo desigual (ibíd.); relacionalidad que se sale de toda adecuación pensante para desbordar todo artilugio de apresamiento. Esta relación fue inconcebible para la mayoría de la filosofía moderna; en ella, el yo podía resolver todos sus problemas con su entorno circundante, incluso los de su propia existencia. Pensamiento de lo igual donde el yo erige tanto su saber como su actuar: pensar bien, es actuar bien, es dar cuenta de lo adquirido como obra tematizada en relación soluble que aclara todo acerca del otro.

Para Levinas, lo problemático de esta reducción "identitaria" no es sólo la adecuación envolvente del otro en el Mismo; su denuncia radical es ver cómo la filosofía occidental ha negado la existencia de la desproporción entre el acto y lo que el acto hace acceder: es decir, el trayecto de la relación, proximidad puesta por fuera de toda correlación y adecuación "originaria" por parte del yo. Un gran reto para la filosofía moderna y en sí, para las ciencias del hombre. Podríamos preguntarnos entonces: ¿es posible acceder al Otro más allá de un pensamiento que lo piensa y aún así, no perder la relación de alteridad? Es como decirle al pensamiento que no piense, a la mirada que no vea y a la conciencia que no se acerque intencionalmente.

Esta negación del ser a lo idéntico, ser des-provisto de toda investidura pensada constituye un yo puesto a merced del Otro, es decirle al Mismo que existe la idea de un Otro más allá de sus facultades mentales; Otro -distinto al (otro) de la modernidad- que lleva al Mismo hasta el límite del delirio y lo recusa de su adecuación saber-ser; Otro que lo retrocede al acto originario del acto (lo in-actual), del pensamiento pre-reflexivo que revela un tiempo propio, una interioridad, una singularidad. En esta "inadecuación" (a-totalizante) la determinación del Mismo pierde hidalguía y finitud al ser lanzado a un más allá que le hace encontrarse con un ser con rostro de carne y hueso: la instauración a un caraa-cara. Pasividad que re-considera la desproporción de esa idea -tan anti-griega diría el mismo Levinasque se sale de un pensamiento igualitario, y que aún así, puede ser pensada por él. Resplandor de lo infinito en acto finito, desmedida de la correlación, desmesura de la adecuación.

En este sentido, ¿le quedará algo que pensar al ser respecto al otro en la finitud de su pensamiento? Levinas respondería a esta pregunta argumentando que, precisamente, "la separación es la constitución misma del pensamiento y de la interioridad; es decir, de una relación con la independencia" (1977, p. 126). Siendo así, el pensamiento no desaparece al desbordar la adecuación ser-saber; por el contrario, pensar es acción "objetivante" que se coloca como sospecha vigilante a todo intento de englobamiento finito por parte del Mismo. Pensar, en esta línea de pensamiento, ya no es actuar bien, inversamente, es estar separado de, a fin de responder a. Por consiguiente, la radical separación que conserva la 
relación Mismo-Otro es el lugar donde se produce precisamente lo Infinito. Paradoja de un pensamiento que conjuga la inexplicable-explicación de estar frente-a-Otro (ser en cuestión) que no podemos poseer y no por ello, estar exentos de pensarlo como ser separado; más aún, responder por él. Pensamiento asimétrico que mantiene el infinito en lo finito; el más en el menos; el modo de ser por el cual "un ser separado, fijado en su identidad, el Mismo [...] contiene sin embargo en sí lo que no puede contener más de lo que es posible contener". (Levinas, 1977, p. 52). Acción que sólo puede concebir-se por la virtud de su subjetividad.

Ahora bien, ¿cómo es posible la total separación Mismo-Otro sin malograr o perder, en ningún momento, la relación? ¿Cómo palpar esta separación relacional? Nuestro filósofo de la alteridad considera que sólo en la piel es donde el Rostro se hace presente; carne de mi carne que se desgarra como infinito para dejarse ver desnuda y libre de toda máscara, "rostro que está cerca, contacto de una piel; rostro que se espesa como piel" (Levinas, 1987, p. 152); infinito hecho carne que deshechiza al rostro de la multiforme mistificación y el apresamiento en una conciencia intencional (Ver al respecto: Jaramillo y Aguirre, 2009) ${ }^{10}$. Por consiguiente, infinito es carne gracias al Rostro desnudo del Otro, rostro libre de todo acto objetivante y finito: "el infinito me viene a la idea en la significancia del rostro" (Levinas, 1991, p. 97). No es posible concebir el Rostro fuera de la infinición que produce lo infinito. Concebir el rostro fuera del infinito es enmascararlo por las capas

10 En entrevista con $\mathrm{Ph} \mathrm{Nemo}$, Levinas corrige a éste cuando pregunta ¿en qué consiste y para qué sirve una fenomenología del rostro? Ante lo cual él responde que "no se puede hablar de una fenomenología del rostro en tanto la fenomenología describe lo que aparece; por lo mismo, tampoco se podría hablar de una mirada vuelta hacia el rostro, pues la mirada es conocimiento y percepción (Levinas, 1991, p. 79). Se presenta así una doble mistificación: la primera se relaciona con la mirada vuelta hacia [...], lugar común en el mundo donde la filosofía moderna ha apresado el rostro en la correlación saber-ser; la segunda mistificación hace alusión a la conciencia intencional, lugar donde se adecúa perfectamente el rostro en tanto, fenomenológicamente en este caso, todo rostro sería rostro de 0 rostro para[...]En ambos casos, se presenta el rostro como objeto, como tema, donde "ser objeto, ser tema, es ser aquel del cual puedo hablar con alguien que ha atravesado el plano del fenómeno y me ha asociado a él" (Levinas, 1977, p. 122). temáticas de un pensamiento moderno. Es por ello que la radical superación del Otro en el Mismo es denominada por Levinas: "Rostro", superación que sólo es posible gracias a la participación de lo infinito en la relación; infinito que hace estallar los cuadros de todo contenido pensado donde queda abarcado el otro. Es gracias al concepto de Rostro, que la propuesta levinasiana está lejos de ser abstracción teórica o idealismo trascendental. Concepto, a nuestro parecer, oportuno para la reflexión contemporánea de las Ciencias Sociales; incluso de las Ciencias Naturales, pues la técnica "desmitifica el universo. Deshechiza la naturaleza. Por su universalidad abstracta choca imágenes y pasiones. Pero ha descubierto al hombre en la desnudez de su rostro" (Levinas, 2004, p. 291).

"Rostro" aquí no está entendido en su sentido fisonómico (color de los ojos, forma de la nariz, frescura de las mejillas); es decir, gesto propio de la corporalidad o representación física del ser. Para Levinas el 'Rostro' es esa "posibilidad que tiene lo humano de significar -en su unicidad, en la unidad de su desembozo y de su mortalidad- el señorío de su llamada a mi responsabilidad respecto a él" (Levinas, 2001, p. 279). Rostro que se revela al expresarse desde una interioridad; por tanto, es más que imagen que se muestra o cuerpo que realiza; Rostro es relación asimétrica en la que Mismo-Otro conservan su total exterioridad por la acción de lo infinito.

Lo infinito de la relación muestra (revela) un rostro liberado de la mirada abarcante del mismo, decantada, muchas veces, en la mordaz tipificación de un rol; liberación que lo deja al desnudo, lejos de todo solapamiento y atributo locuaz; rostro sin adornos, sin encajes decorativos puestos al servicio del Mismo. Gracias al infinito, rostro es rostro en su desnudez. Orfandad que excede el ser sobre la finalidad desligado de toda formalidad tematizante; en su desnudez, su sentido ya no sería para otros sino para sí. Rostro desnudo que se opone a ser de-velado y ofrecido a los poderes del Mismo; rostro que se "prolonga en la desnudez del cuerpo que siente frío y vergüenza de su desnudez" (Levinas, 1977, p. 98).

No obstante, ¿si el rostro se expone desnudo no correría el riesgo de quedar a merced de los poderes del Mismo? Trampa de apresamiento que 
Levinas controvierte de dos maneras. En primer lugar, contrario a lo que se podría pensar, el rostro hecho tema o tipificado está más al acecho que la indefensión de un rostro puesto al desnudo; el rostro desnudo no sólo presenta una orfandad, muestra también un señorío al revelarse libre de toda adecuación; por tanto, es alguien que se muestra tal y como es, sin necesidad de dar cuenta de sí; es por consiguiente lo que es y no lo que el tema hace o dice de él; indefenso y revestido de humanidad: su verdadera humanidad. En segundo lugar $-\mathrm{y}$ unido a lo anterior- el rostro desnudo se muestra como alguien donde se expone la existencia de un ser que suplica desde su misma humanidad; en él podemos ver no sólo una vergüenza sino también una miseria; sin embargo, es rostro que exige desde su misma des-protección. Rostro que "sólo puede suplicar porque exige, privado de todo, porque tiene derecho a todo y que se reconoce al dar" (Ibíd.). Es precisamente en esta segunda contraversión donde Levinas utiliza la palabra Epifanía ${ }^{11}$. En la epifanía, el rostro se muestra con total señorío, como alguien que pide y pone en-cuestión; Otro con rostro que carece de máscara por su desnudamiento; en él, se ve un hambre y una desnudez hecha indigencia. Rostro que se expresa más allá de lo dicho y "pide como se pide algo que se ordena, como cuando se dice: “ise os ruega que...!”' (Levinas, 1991, p. 92). Epifanía del rostro que se revela con indigencia y a su vez con altura: ambigüedad que se exhibe como desposeído-señor, huérfano-maestro, extranjerohermano, siervo-rey.

De esta manera, desnudez y epifanía juegan un papel preponderante en el rostro del Otro gracias a la producción de lo infinito ${ }^{12}$ en la relación MismoOtro. Por un lado, se encuentra un rostro que exige "otro modo que ser" observado al exponerse desnudo al Mismo; por otro, su desnudez invoca una

11 Este término podría entenderse, atendiendo a su etimología, a la presentificación del Otro como "manifestación". El término ha adquirido matices sagrados, por lo que la "epifanía" podría definirse como la revelación del Otro, entendido éste como dotado de "santidad" o absoluta separación.

12 Producción entendida en su doble acepción: como verbo esencial de la operación por la cual a la vez, se gesta el ser de una entidad y por la cual se revela (Levinas, 1977). responsabilidad que va más allá de la necesidad. Todo esto es posible por la acción desbordante de un pensamiento omni-abarcante; acción que no lo destruye, sino que lo excede y lo estremece en el asombro de una alteridad radical o absoluta. De esta manera, el Rostro no se revela con violencia a la finitud, no se instaura en la negatividad, no es resistencia que arremete y agrede; por el contrario, es rostro que se recibe positivamente al salirse del plano meta-físico del ser para ingresar al plano ético de una alteridad absoluta. Así pues, asumir el rostro en su eticidad es, de entrada renunciar a la posesión de los poderes del mismo, poderes que no lo debilitan; por el contrario, le otorgan su capacidad de poder asumirlo con Altura ${ }^{13}$, invocar por una creatividad tal que obligan al mismo a ser mirado De Otro modo que ser o más allá de su esencia. Reto imperante que exige a las Ciencias Sociales considerar lo humano más allá de unos derechos (derechos humanos) y más acá de unos deberes (deberes ciudadanos). Reto que se instala en el plano de lo ético como lugar de resistencia donde se encuentra "la piel de un Rostro que se mantiene más desnuda, más desprotegida" (Levinas, 1991, p. 79).

Con base en lo anterior, la ética que propone Levinas contraviene cualquier resistencia, paraliza los poderes porque otorga poder; es una ética hecha rostro de pobre al que todo se debe. Rostro que sólo puede darse de manera ética porque en ella se desanuda el control y el dominio de toda acción comprehensora. La ética revela el rostro en su completa desnudez para que pueda expresar sin la mediación de la imagen plástica que le opaca. Se otorga poder al Otro para expresarse a través de su rostro, poderes emergentes de una vida interior que se expresa en el decir del acontecimiento; expresión que sólo puede darse en el cara-a-cara, en el solicitar una respuesta a mi llamado y en esperar una pregunta de su discurso; expresión que se impone al Mismo desde una desnudez y un hambre, sin posibilidad de emplazamiento o justificación por su

13 La idea de altura concilia la contradicción que opone espontaneidad a sumisión: si la sumisión al Otro (Autrui) no le arrebata al acto su dignidad de movimiento espontáneo, es que el Otro (Autrui) no está solamente fuera, sino ya como altura (Levinas, $2001^{\text {a }}$, p. 103). 
no entendimiento, "de suerte que, en la expresión, el ser que se impone no limita sino que promueve mi libertad, al suscitar mi bondad" (Levinas, 1991, p. 214). Por consiguiente, reiteramos el interrogante expuesto ya hace algunos años: ¿en la inadecuación dada por lo infinito es posible un conocimiento del Otro, o estamos condenados a la incertidumbre? La pregunta sigue aún vigente y de su posible respuesta dependerá la adopción de distintas posturas epistémicas para los Estudios Sociales (Aguirre y Jaramillo, 2006, p. 67).

Concluyendo con el presente apartado, podemos decir que el rostro, más que ente que se expresa facialmente (le visage), es Rostro porque habla, que se revela en lo infinito para dar testimonio del mandato originario que precede todo pensamiento de adecuación. Antes de cualquier develamiento del ser, antes de cualquier acción tematizante, antes de cualquier constatación objetiva; incluso, antes de cualquier virtuosidad hecha caridad, gritará la voz del "Rostro" para resistir cualquier enmascaramiento; su desnudez desdice el dicho que lo cubre para revelarse (y rebelarse) ${ }^{14}$ fuera de todo enmascaramiento hecho obra. Conocimiento ya no de lo adecuado sino de lo "Deseable", que como se expresaba anteriormente: es "Deseo [que] mide al infinito porque es medida en tanto que imposibilidad misma de medida" (Levinas, 1977, p. 285). Así podríamos decir que: la desmesura medida por el Deseo es Rostro.

\section{Lenguaje y Ciencias Sociales: entre la retórica de la injusticia y la instauración de la significación}

La crítica levinasiana a la totalidad y la propuesta de recibir al Otro como infinito nos han llevado a considerar el Rostro como posibilidad de relación; obviamente, la infinitud del Otro no puede caer en las abstracciones que caracterizan la totalidad, aunque tampoco pueden reducirlo a mera carne y figura. El apartado anterior terminó reivindicando la voz del Rostro y, en efecto, el lenguaje juega un rol central en la propuesta de Levinas. Pero, ¿acaso

14 Para una mejor comprensión de este aparente juego de palabras, ver: Jaramillo, 2008. el lenguaje no ha sido una cuestión recurrente, al menos en las últimas décadas?, ¿está Levinas en la onda de lo que se denominó el "giro lingüístico"? Sin lugar a dudas, su propuesta con respecto al lenguaje merece un amplio y detenido desarrollo, pues la forma de tejer sus ideas puede llevarnos a parajes muy lejanos a los que originalmente quiere conducirnos. El análisis en este apartado se dedicará a mostrar cómo el lenguaje se puede tornar retórica que confunde y seduce; de igual modo, se ligará discurso y ética y, finalmente, se propondrá cómo las Ciencias Sociales están llamadas a instaurar la significación.

Partamos de la premisa según la cual la verdad que brota de la relación Mismo-Otro asume un sentido dual: por un lado, si se entiende en su originalidad, impide la adecuación, pues cada uno conserva la autonomía del ser separado; por otro lado, permite franquear la distancia, aunque sin formar totalidad con la "otra orilla". Lo que permite establecer relación, en este segundo modo, reposa en el lenguaje: "relación en la que los términos se absuelven en la relación, siguen siendo absolutos en la relación. Sin esta absolución, la distancia absuelta de la metafísica sería ilusoria" (Levinas, 1977, p. 87). De manera que sin el lenguaje, no habría posibilidad de alcanzar la verdad y, más que eso, no habría ninguna posibilidad de encuentro con el Otro, con su Rostro pues, en definitiva, "el rostro es una presencia viva, es expresión [...] El rostro habla. La manifestación del rostro es ya discurso 15" (Levinas, 1977, p. 89).

Hay que aclarar, pese a todo, que cuando se habla de lenguaje es preciso hacer ciertas distinciones, pues no todo discurso es relación con la exterioridad. Es muy común leer reflexiones sobre el lenguaje y su relevancia en la investigación cualitativa, sin embargo, muchas de tales reflexiones podrían caer en lo que Levinas denomina retórica la cual, aunque conserva un tipo de relación interpersonal (no es entre persona y cosa, sino entre persona y persona; recordemos que aún la retórica sigue siendo dis-

15 En este sentido, 'discurso' no se plantea como un decir hueco, como palabrería agotada. Según Levinas: “El discurso no es simplemente una modificación de la intuición (o pensamiento), sino una relación original con el ser exterior" (Levinas, 1977: 89). 
curso y, en esa medida, solicita el libre asentimiento del otro), plantea tal relación en términos de violencia: "la naturaleza específica de la retórica (de la propaganda, de la adulación, de la diplomacia, etc.) consiste en corromper esta libertad. Por esto es violencia por excelencia, es decir, injusticia" (Levinas, 1977, p. 93). Esto se hace evidente cuando se desarrollan, por ejemplo, investigaciones sobre lo étnico, con el interés de configurar representaciones idílicas sobre las personas que conforman una comunidad, deformando sus propias vivencias en aras de un mercado académico que demanda relatos exóticos. También es el caso de investigaciones que responden a intereses de clase o a intervencionismos sociales, en las cuales el investigador se yergue como el detentor de respuestas o soluciones, aguijoneador de las conciencias dormidas.

La recuperación del lenguaje como posibilidad de encuentro, como conversación ${ }^{16}$, se hace vital en las Ciencias Sociales, tanto en su línea epistemológica como metodológica. En Levinas, es necesario renunciar a las pretensiones retóricas inmersas en lo que él denomina psicagogia, demagogia, pedagogía; es decir, hay que abordar al Otro no mediante escorzos o perfiles tematizantes, sino de frente, en un verdadero discurso: "es necesaria la relación del discurso para "dejarlo ser": el "develamiento" puro, en el que se propone como un tema, no lo respeta suficientemente. Llamamos justicia a este acceso de cara, en el discurso" (Levinas, 1977, p. 94). Como puede notarse, el lenguaje se desplaza ahora de su mera pretensión cognoscitiva hacia una dimensión de justicia. No obstante, justicia en Levinas no remite a igualdad entre personas; él es claro en reclamar que el Otro es Maestro, del Otro yo aprendo, el Otro no es igual a mí, el Otro me trasciende en su Altura; de esta manera se constituye la posibilidad

16 Como adecuadamente lo plantea Hendley: "Lo que parece que necesita aquí Levinas es una explicación de cómo "todo recurso a las palabras" presupone un uso conversacional del lenguaje y, por tanto, el sentido de obligación con el otro exigido por esa práctica conversacional" (2004, pp. 154-155). Es necesaria una reflexión multidisciplinaria sobre el fenómeno de la conversación, en la medida en que es el ámbito por excelencia, la reflexión sobre lo humano (una aproximación a esta discusión puede encontrarse en Aguirre, 2006a). de la verdad. En consecuencia, "la sociedad no se desprende de la contemplación de lo verdadero, la relación con el otro, nuestro maestro, hace posible la verdad. La verdad se conecta a la relación social que es justicia. La justicia consiste en reconocer en otro a mi maestro" (Levinas, 1977, p. 95).

Así pues, la reflexión sobre el lenguaje se anclaría en el terreno ético. Tradicionalmente se ha visto el diálogo como un encuentro de personas que utilizan el lenguaje para exponer sus razones en aras de consenso o aclaración; en ese sentido, se requeriría un lenguaje común, una razón común en la que se traduzca lo pensado: "sólo habría razón en el individuo pensante en la medida en que entrase él mismo en su propio discurso, en el que, en el sentido etimológico del término, el pensamiento comprendería al pensador, lo englobaría" (Levinas, 1977, p. 96). Discurso es tradicionalmente entendido, entonces, como un decir coherente, como coherencia de los conceptos y, en conclusión, se suprimiría lo irracional (incluido, claro está, lo sensible) en aras de una argumentación lógicamente construida. Levinas ve en esto una supresión de lo Otro, pues lo Otro existe en el discurso en tanto pueda ser representado y pensado y, como anotamos anteriormente, la representación y el pensamiento se inscriben en el ámbito del sistema, de la Totalidad.

Ahora bien, la obra del lenguaje no puede reducirse a un juego de razones y a un intento por acoplarlas con las exigencias de un sistema universal; en vez de ello, tal obra:

Consiste en entrar en relación con una desnudez desligada de toda forma, pero que tiene un sentido por sí misma [...], que significa antes que proyectemos la luz sobre ella [...] La desnudez del rostro no es lo que se ofrece a mí para que lo devele y que, por esto, me sería ofrecido, a mis poderes, a mis ojos, a mis percepciones en una luz exterior a él. El rostro se ha vuelto hacia mí y es esa su misma desnudez. Es por sí mismo y no con referencia a un sistema (Levinas, 1977, p. 98).

Este por sí mismo, no tematizado como se tematizan los objetos, es la desnudez de un Rostro que siente hambre y frío, Rostro indigente; su 
reconocimiento no se traduce en darle una categoría ni filosófica, ni sociológica, ni antropológica; reconocer es dar: "pero dar al maestro, al señor, al que se aborda como "Usted" en una dimensión de grandeza” (Levinas, 1977, pp. 98-99). De este modo, el lenguaje podrá asumir otra característica en las Ciencias Sociales, la de instaurar originalmente la significación; obviamente, ya lo habíamos visto con la hermenéutica, las Ciencias Sociales han tenido siempre esta pretensión; sin embargo, lo han hecho encerrados en el juego de los signos. Según Levinas, si intentamos comprender la significación a través de los signos, continuaríamos reduciendo el Otro a simple representación, imagen congelada en la conciencia. La significación auténtica (cuyo acontecimiento original es el caraa-cara) es la que hace posible todo signo (Aguirre y Jaramillo, 2006).

En conclusión, el lenguaje no sucumbe ante la pretensión de su comprensión, de encerrarlo en un sistema de signos susceptible de codificación o decodificación; el lenguaje trasciende la reciprocidad de los términos, aunque posibilita el encuentro. Es de resaltar que el lenguaje no se plantea en neutralidades conceptuales, sino que asume el carácter de conversación donde el Otro se revela en su rostro y es recibido en su manifestación previa a cualquier objetivación. La función de las Ciencias Sociales de instaurar significado consistirá en dislocar la obsesión por el sentido y acoger la responsabilidad para con el Otro, lo que en últimas significa invocar la pasividad de un yo tradicionalmente activo y orgulloso en su conciencia, conciencia que fracasa al pretender ser Midas que convierte todo en representación.

\section{Aproximaciones epistemológicas}

Como lo expresamos anteriormente, la Ciencias Sociales habrían de nacer a mediados del siglo XIX en contraposición a unas Ciencias Naturales imperantes, que erigían su método (nomotético) como acción de validez vinculante entre hecho y teoría. Su emergencia se hizo manifiesta por problemas de tipo social que poco importaban a los científicos "naturales" y que sí empezaron a ser apremiantes en otros círcu- los de reflexión o ciencias noveles como la Historia, la Economía y la Sociología. Estas ciencias, en sus primeros desarrollos, comenzarían a preguntarse por la estructura de la sociedad, la manera como se sistematiza la historia, y con ella, las diferentes acciones e interacciones humanas. No obstante, en un intento de sistematización, éstas ceden a la tentación de presentar sus hallazgos teóricos o investigaciones bajo el modelo clásico de ciencia newtoniana (Gaitán, 2008).

Con ellas, el positivismo es puesto en cuestión para abrir paso a tradiciones filosóficas como la hermenéutica, llevando así a una disputa metodológica: ciencias nomotéticas y ciencias ideográficas. En las primeras, el investigador cuestiona la naturaleza y le exige por tanto un saber; es un sujeto activo que se formula permanentemente hipótesis y teorías, plantea instrumentos cada vez más precisos, contrasta coherentemente sus conjeturas y las expresa en un lenguaje matemático explicando la realidad. En las segundas, por el contrario, más que interrogar la naturaleza, se preguntan por un sujeto histórico a partir de su pertinencia con la realidad donde las instituciones y construcciones humanas son vistas como expresiones de la vida o como bien lo llamara Dilthey: "Las Ciencias del Espíritu".

Precisamos, entonces, que las diferencias entre ambas tradiciones no fueron solamente cuestiones de procedimiento -así en sus comienzos haya sido el punto más álgido para la discusión, Levinas dirá: "Su verdad primera es de orden metodológico" (1998b, p. 81)-; sin embargo, es necesario precisar que las diferencias también estribaron en una serie de dificultades relacionadas con un conocimiento de lo social, el papel del científico y los procesos de relación "objetiva" entre investigadores e investigados. Diferencias como:

Los objetos de estudio (personas o cosas), la parcial identidad que se establece entre sujeto y objeto de conocimiento (lo que ocasiona que el investigador se vea afectado y a su vez afecte de modos diversos a sus objetos), la obtención de un conocimiento basado en leyes (la dificultad de generalización propia de muchos campos de lo 
social) y finalmente, los dilemas éticos vinculados a la experimentación en el ámbito de lo humano (Gaitán, 2008, p. 2).

Sin embargo, a pesar de la marcada diferencia entre ambas, las Ciencias Sociales aún no han podido desprenderse con total independencia de la tradición newtoniana, en tanto, aún le apuestan a cierta neutralidad valorativa, a la creación de leyes generales con un soporte empírico y a la conformación de comunidades que validan sus avances heurísticos y de investigación. Las Ciencias Sociales aún siguen siendo extrañas para el concierto general de los seres humanos, como lo expresara Fuller (1997, p. 1): "Normalmente pensamos acerca de la ciencia como diferente del resto de la sociedad, para pensarla como una actividad social normal, necesitamos alejarnos de nuestra actitud normal hacia ella, parece que al público se le da sólo un grupo de lentes con los cuales observar la ciencia contemporánea”. Aún así, cada vez es más creciente el número de científicos sociales que establecen procesos de empatía con los sujetos de su estudio y se abstienen de hacer generalizaciones demasiado amplias en sus postulados; ello gracias a la flexibilidad de los diseños cualitativos y la multiplicidad de métodos que cada vez son más crecientes en los ámbitos de la investigación social.

Lamentablemente, la pertinencia de las Ciencias Sociales se ha centrado, en muchas ocasiones, en la multiplicidad metodológica y no en ser abordada desde sus fundamentos éticos y epistemológicos. Preocupación indispensable, ya que no enfocaría la reflexión sólo en los procedimientos, sino que iría -a las cosas mismas- de las ciencias del hombre: el ser humano y sus procesos de interacción. He ahí la pertinencia de un autor como Levinas, pues éste se separa de una visión filosófica moderna de univocidad metódica de asunción del otro (la linealidad Mismo-Otro), para instalarse en los campos de una ética como filosofía primera en tanto alteridad y trascendencia.

Si bien Levinas no centró su pensamiento en la fundamentación de las Ciencias Sociales, sí podemos otear en sus reflexiones posibilidades de fecun- dación epistémica ${ }^{17}$ acerca de nuestra concepción y acercamiento al Otro. Intentar deshechizar las ciencias de su cerrazón teórica y humanismo pueril, que muchas veces se traslapan en discursos clericales y románticos ocultando un mundo lleno de exclusión y miseria, trampa en la que cayó el humanismo europeo al instaurarse en la impronta ambigua del discurso retórico, sin contacto con una realidad donde habitan los excluidos y los explotados.

En tal sentido, bosquejamos tres postulados críticos con el fin de abrir una nueva brecha para pensar la investigación social. El primer postulado tiene que ver con el formalismo social impuesto para domesticar las acciones humanas: el investigador, gracias a sus presupuestos teóricos, se convierte en sujeto de obras para decir y pos-decir todo acerca del sujeto investigado, lugar de adecuación que oculta o enmascara su rostro, dejándolo a entera disposición de la obra ${ }^{18}$. El segundo tiene que ver con visiones maniqueas e idílicas que se tienen acerca del otro investigado, puntos de vista que terminan alineando la singularidad a la mismidad del investigador. El tercer punto crítico hace referencia a los procesos de formación de los investigadores sociales; procesos en los que se les forma para explicar o comprender a las comunidades locales bajo la mismidad de una sociedad injusta que discursivamente apela a derechos de igualdad. A continuación explicitaremos de manera sucinta cada uno de ellos.

El formalismo de las prácticas sociales: para Foucault (2001) el surgimiento de las Ciencias Sociales se encontró ligado a la emergencia de disciplinas como un intento de abordar las prácticas sociales de los sujetos; los saberes que comportan dichas prácticas hacen parte de las formas de relación intersubjetiva. De este modo, a las disciplinas,

17 'Epistemología fecundante' entendida como aquella que lleva consigo un pensamiento reflexivo del conocimiento en confrontación consigo mismo, con sus pares e impares (otros) y con su mundo; epistemología movida por el viento, la cual reacciona frente a aquellos adelantos científic os que el sujeto se niega aceptar, ciega y acríticamente. Lo producido "como científico", por el científico social y natural, debe ser continuamente depurado en procesos subjetivos e intersubjetivos de reflexión (Jaramillo, 2003).

18 Por 'obras' entendemos aquellas producciones que del intelecto humano, se condensan en textos escritos, y que reflejan un conocimiento cerrado y objetivo de la realidad. 
en su intento de volverse omni-comprensivas, se les escaparon los saberes a través de los intersticios de sus postulados científicos; son los sujetos sociales los que significan el mundo emancipadamente. Los saberes son prácticas que van más allá de las disciplinas o ciencias humanas; saberes que las desbordan porque son parte, según Levinas del "misterio humano"; así sea "denunciado [por éstas] como ignorancia y opresión" (1998b, p. 82).

Por lo general, en investigación se da más preeminencia a antecedentes de marcos lógicos en torno a un objeto de estudio (que obviamente son importantes), que a las prácticas de los sujetos relacionados con esos saberes. Los tiempos internos de los sujetos implicados son igualmente importantes en la configuración del proyecto, tanto como los referentes conceptuales que los sustentan. En tal sentido, se hace necesaria esa actitud fenomenológica del investigador del ir a las cosas mismas, "lo que significa ante todo no atenerse a las palabras que sólo mientan una realidad ausente" (Levinas, 2005b, p. 68), realidad no percibida, escondida en las hojas de los libros, privada de ser tocada. Esto invoca a que el investigador se pregunte si el conocimiento emergente de su proyecto proviene de un mundo teórico objetivo o si, por el contrario, tiene múltiples formas de trabajo científico; es decir, está regado en novelas, relatos, expresiones artísticas, reportajes, etc. (Jaramillo, 2006).

La visión del Otro: una preocupación principal en las Ciencias Sociales son los sujetos sociales; seres que responden a heterogeneidades caracterizadas por tiempos y lugares construidos objetiva y subjetivamente, "actores"19-y no objetos- que hacen parte de los procesos de investigación (Zemelman, 2006). A veces se considera que por tratarse de seres humanos, se tiene una total comprensión acerca de la trascendencia y altura del Otro en sus procesos de alteridad; sin embargo, en la praxis, el otro que

19 Dado que 'actor' puede connotar cierta simulación, asumimos mejor la noción de sujeto, el cual no es una simple forma de la razón, sino Sujeto en tanto "es capaz de movilizar el cálculo y la técnica del mismo modo que la memoria y la solidaridad, y sobre todo al combatir, indignarse, esperar, inscribir su libertad personal en las batallas sociales y liberaciones culturales. El sujeto, más aún que razón, es libertad, liberación y rechazo" (Touraine, 2000, p. 67). se estudia se torna instrumental. Lo anterior, se presenta desde dos perspectivas: la primera tiene que ver con ir al otro en posición de superioridad donde se nos vuelve tema de estudio; se compartimentaliza a fin de ser tratado como población objeto de una investigación. Así, terminamos considerando al otro como exterioridad (como alguien que se encuentra fuera de mí), o como negatividad (distinto a mí), o como temática de estudio (así no hablaremos de niños y niñas sino de infancia o de pobres sino de pobreza) (Skliar, 2006, p. 256). En el segundo caso, el investigador va con una mirada más implicativa, con su conciencia abarcadora que el otro no es sólo fuente de datos sino alguien igual a mí; adecuación del otro a partir de la experiencia del mismo. En ambas posiciones el otro pasa a ser un anónimo, ser de obras que circula de mano en mano, constatado a partir de pre-figuraciones empíricas y moldeado perfectamente al gran corpus de la teoría.

Recordemos que para Levinas el otro no es adecuación a un sujeto cognoscente, sino que es un sujeto que se nos presenta como rostro; rostro en la medida que no es reductible a la apariencia, ni menos a caretas de personajes. Para tal fin, se hace "necesario que aparezcamos el uno para el otro, no como si estuviéramos yuxtapuestos, sino convencidos de que yo soy mi exterior y el cuerpo del otro es él mismo. Sin esta concepción, seguiría el pensador [investigador] creyendo que el cuerpo del otro es un accidente que obstaculiza su objetivación; o, a lo mejor, reduciendo el Otro al Mismo, creyendo totalizar el infinito que encierra" (Aguirre, 2006b, p. 71). La formación de los conceptos que se tienen del Otro es más que alcanzar conocimiento a partir de consensos en los que se garantizaría la objetividad del saber, siempre y cuando haya un acuerdo entre las múltiples subjetividades. El Otro nos "arranca de nuestra hipóstasis, del aquí, del corazón del ser o del centro del mundo en donde yo me pongo a mí mismo como privilegiado [...] la reducción intersubjetiva describe la posibilidad asombrosa o traumática de ese desengaño en el que el yo, frente al otro, se libera de sí, despierta de su sueño dogmático" (Levinas, 2001b, p. 109). 
Este proceso de ver al otro como absolutamente Otro pasa a ser de vital importancia en las Ciencias Sociales, pues la visión que se tenga del Otro, partirá su relación intersubjetiva y los ensanchamientos de horizonte de vida; lo que va más allá de ser una relación cognitiva, relación más bien ética y espiritual: "quizás lo espiritual no muestre -no revele- su especificidad más que cuando se interrumpe la rutina del ser: en la extrañeza de unos humanos ante los otros, que sin embargo son capaces de una sociedad cuyo vínculo ya no es la integración de las partes en un todo (Levinas, 2002, p. 117). Amar al Otro en la no-indiferencia, sino en su rostro humano es nuestro principal reto en la investigación.

Formando en la Totalidad: La época moderna se caracterizó por una formación que propugnaba la experticia, el desarrollo de talentos y el tener cierta edad para resolver problemas del mundo adulto. Formarse quería decir aquellas obligaciones que tiene el sujeto para consigo mismo al no dejar oxidar los propios talentos. Concepto Kantiano de formación que se alejaba de la vida y la vivencia que, según Gadamer, son aquellas disposiciones que tienen en cuenta la experiencia del sujeto que se forma a partir de la interacción. Humboldt sugiere un sentido de formación que diferencia la cultura (que según la modernidad forma para la técnica y el talento) de la formación del ser: "cuando en nuestra lengua decimos formación (Bildung) ${ }^{20}$, nos referimos a algo más elevado y más interior, al modo de percibir que procede del conocimiento y

20 El término alemán 'Bildung', que se traduce como "formación", lo entendemos como la cultura que posee el individuo como resultado de su formación en los contenidos de la tradición de su entorno. del sentimiento de toda la vida espiritual y ética y se derrama armoniosamente sobre la sensibilidad y el carácter (Gadamer, 1983, p. 86). Formación en este sentido, no quiere decir sólo el desarrollo de talentos o capacidades, ella es y hace parte de la vida interior del hombre.

En la formación no sólo intervienen las capacidades y talentos de una razón ilustrada, también participa una vida valorada y fundamentada en una ética no impuesta en procesos de alteridad. Formación que emerge en el devenir del tiempo, que hace historia y se dinamiza al no quedarse sólo en lo experto de la academia, sino que trasciende, avanza y toca al sujeto en su multi-dimensionalidad. En el ámbito formativo, se observa que las Ciencias Sociales le apuestan a un sujeto que necesita ser formado para cierto tipo de sociedad; es decir, el otro se forma con base al tipo de hombre y humanismo imperante; y ello no sólo desde los ámbitos escolares, sino en la manera como se instruye a los científicos actuales. Un investigador que plantea postulados para la mismidad de la sociedad presente (Totalidad) y que poco cuestiona tal alienación, se convierte en un ser preso de fuerzas que los dirigen a sus espaldas y toma prestado un sentido para seguirse moviendo en medio de sus obras (Levinas, 1977). Se entrena un investigador para que compruebe teorías producto de observaciones empíricas que posteriormente constata y presenta a un público ilustrado; sin embargo, la vida, la verdadera vida [...] aún sigue ausente.그 


\section{Bibliografía}

Aguirre, J. (2007). "El concepto 'Morada' como categoría posible para la fundamentación de una ética ambiental”. En: Revista Luna Azul (en línea), n. ${ }^{\circ} 25$ (Julio - Diciembre). Obtenido desde [http://lunazul. ucaldas.edu.co/downloads/Revista25_9.pdf]

Aguirre, J. (2006a). "Estatus epistemológico de la conversación y sus aportes a la práctica investigativa”. En: Cinta de Moebio (en línea), n. ${ }^{\circ} 25$ (Marzo). Obtenido desde [http://www.csociales.uchile.cl/publicaciones/ moebio/25/aguirre.htm]

Aguirre, J. C. (2006b). La fenomenología como fundamento de las ciencias humanas. Tesis para optar al título de Magíster en Filosofía de la Ciencia. Programa de Filosofía. Universidad de Caldas. Manizales.

Aguirre, J., Jaramillo, L. (2006). “El Otro en Levinas: una salida a la encrucijada sujeto - objeto y su pertinencia en las ciencias sociales". En: Revista Latinoamericana de Ciencias Sociales, Niñez y Juventud, vol. 4, n. ${ }^{\circ}$ (Julio-Diciembre), pp. 47-71.

Alford, C. F. (2002). "The opposite of totality: Levinas and the Frankfurt School". En: Theory and Society, vol. 31, n. ${ }^{\circ} 2$ (Abril), pp. 229 - 254.

Burggraeve, R. (2005). "The good and its shadow: the view of Levinas on human rights as the surpassing of political rationality". En: Human Rights Review, vol. 6, n.o $^{2}$, (Junio), pp. 80 - 101.

Critchley, S. (2004). "Introducción a Levinas". En: Levinas, E. Difícil Libertad. México: Editorial Fineo, pp. $11-39$.

Dueck, A., Parsons, T. (2007). "Ethics, Alterity, and Psychotherapy: a Levinasian Perspective". En: Pastoral Psychology, vol. 55, pp. 271-282.

Dussel, E. (2004). "Lo político en Levinas (hacia una filosofía política crítica)”. En: Barroso, Moisés; Pérez, David. Un libro de huellas. Aproximaciones al pensamiento de Emmanuel Lévinas. Madrid: Trotta. pp. $271-293$.

Foucault, M. (2001). Las palabras y las cosas, una arqueología de las ciencias humanas. México: Siglo Veintiuno Editores.

Gadamer, H. (1993). Elogio de la teoría, discursos y artículos. Barcelona: Península.

Gadamer, Hans. (1983). Verdad y Método I. Salamanca: Sígueme.
Gaitán, C. (2008). Sentido de la epistemología en las Ciencias Sociales. Conferencia orientada en el Primer Encuentro Nacional de Historia de la Educación Física, la Recreación, el Deporte y la Motricidad Humana. Facultad de Ciencias Naturales, Exactas y de la Educación, Universidad del Cauca, Popayán, Diciembre 11-13.

Giri, A. (2006). "Creative Social Research: rethinking theories and methods and the calling of an ontological epistemology of participation". En: Dialectical Anthropology, vol. 30, pp. 227 - 271.

Guenther, L. (2007). "Le flair animal: Levinas and the possibility of animal friendship". En: PhaenEx, n. ${ }^{\circ} 2$ (otoño/invierno), pp. 216 - 238.

Fuller, S. (1997). La comprensión pública de la ciencia: nuestro último pánico moral. (Traducido por Dalia Restrepo, 2002). Doctorado en Ciencias Sociales, Niñez y Juventud, Universidad de Manizales - CINDE, pp. 1-39.

Haack, S. (2002). “The same, only different”. En: Journal of Aesthetic Education, vol. 36, n. 3 (otoño), pp. 34-39.

Hendley, S. (2004). "Speech and Sensibility: Levinas and Habermas on the constitution of the moral point of view”. En: Continental Philosophy Review, vol. 37, pp. 153 - 173.

Heidegger, M. (1998). "La época de la imagen del mundo". En: Caminos de Bosque. Madrid: Alianza.

Husserl, E. (1991). La crisis de las ciencias europeas y la fenomenología trascendental. Barcelona: Crítica.

Jaramillo, L. (2008). “La rebelión de la revelación”. En: Segundo Encuentro Nacional por la Vida. Bogotá, Universidad Nacional, Octubre 31 - Noviembre 1.

Jaramillo, L. (2006). Investigación y Subjetividad. La complementariedad como posibilidad para investigar en educación. Tesis para optar al título de doctorado. Universidad de Tras-os-Montes. Vila Real - Portugal.

Jaramillo, L. (2003). “¿Qué es epistemología? Mi mirar epistemológico y el progreso de la ciencia” En: Revista digital Cinta de Moebio, n. ${ }^{\circ}$ 18. Diciembre. Facultad de Ciencias Sociales. Universidad de Chile [http:// www.moebio.uchile.cl/18/frames01.htm]

Jaramillo, L, Aguirre, J. (2008). “Educación y Mundo de la Vida”. En: Revista U.D.C.A. Actualidad \& Divulgación Científica, año $11,{ }^{\circ} .2$, pp. $61-70$. 
Jaramillo, L., Aguirre, J. (2009). “Rostro y Otro: Más allá de la Tematización”. En: IV Jornadas Nacionales Emmanuel Levinas: Perspectivas de Alteridad, Medellín, Universidad de Antioquia, Abril 13-14.

Kant, I. (2000). Crítica de la Razón Pura. 18 ed. Madrid: Alfaguara.

Levinas, E. (2006). Altérité et transcendance. Paris: Librairie Générale Française.

Levinas, E. (2005a). "La filosofía y la idea de lo infinito". En: Descubriendo la existencia con Husserl y Heidegger. Madrid: Síntesis.

Levinas, E. (2005b). "Reflexiones sobre la «técnica»fenomenológica”. En: Descubriendo la existencia con Husserl y Heidegger. Madrid: Síntesis.

Levinas, E. (2004). "Heidegger, Gagarin y Nosotros". En: Difícil Libertad. Buenos Aires: Lilmod. pp. 289 $-291$.

Levinas, E. (2002). Fuera del sujeto. De la intersubjetividad. Notas sobre Merleau-Ponty. Madrid: Caparrós.

Levinas, E. (2001a). "Trascendencia y Altura”. En: La realidad y su sombra. Madrid: Trotta. pp. 85-125.

Levinas, E. (2001b). Entre nosotros: ensayos para pensar en otro. Valencia: Pretextos.

Levinas, E. (1998a). "Prefacio". En: Humanismo del otro hombre. Madrid: Caparrós. pp. $11-17$.

Levinas, E. (1998b). "Sin identidad”. En: Humanismo del otro hombre. Madrid: Caparrós. pp. 81 - 97.

Levinas, E. (1991). Ética e Infinito. Madrid: Rogar.
Levinas, E. (1987). De Otro modo que ser, o más allá de la esencia. Salamanca: Sígueme.

Levinas, E. (1977). Totalidad e Infinito: ensayo sobre la exterioridad. Salamanca: Sígueme.

Lippitz, W. (2007). "Foreignness and Otherness in Pedagogical Context”. En: Phenomenology \& Practice, vol. 1, n. ${ }^{\circ}$. 1, pp. 76-96.

Loumansky, A. (2006). "Levinas and the possibility of justice”. En: Liverpool Law Review, vol. 27, n. ${ }^{\circ}$. 2, (Julio), pp. 147-171.

Skliar, C. (2006). "Fragmentos de amorosidad y de alteridad en Educación". En: Revista Colombiana de Educación, Bogotá, Universidad Pedagógica Nacional, vol. 50, pp. 253-266.

Theocharis, T. (1997). "When did the Science Wars Start?". En: Science and Engineering Ethics, vol. 3, 271-272.

Todd, S. (2003). "Introduction: Levinas and education: the question of implication". En: Studies in Philosophy and Education, vol. 22, pp. 1 - 4.

Tourine, A. (2000). ¿Podremos vivir juntos? El destino del Hombre en la aldea Global. Buenos Aires: Fondo de Cultura Económica.

Van Hooft, S. (2003). "Pain and Communication”. En: Medicine, Health Care and Philosophy, vol. 6, No. 3, pp. 255-262.

Zemelman, H. (2006). "Pensar la sociedad y los sujetos sociales”. En: Revista Colombiana de Educación, Bogotá, Universidad Pedagógica Nacional, vol. 50, pp. 15-33. 
